\title{
ANALYTICAL PERSPECTIVES
}

Article received on April 16 2018

Revised version accepted on May 24 2018

UDC: 781.1:514.116

\section{Dragan Latinčić*}

University of Arts in Belgrade

Faculty of Music

Department of Composition

\section{POSSIBLE PRINCIPLES OF MATHEMATICAL MUSIC ANALYSIS}

\begin{abstract}
The text is a summary of many years of research in the domains of micro-intervals, metric-rhythmic projection of the spectrum harmonics, and the establishment of a link with mathematics, more precisely, geometry, with a special focus on the application of the Pythagorean Theorem. Mathematical music analysis enables the establishment of methods for constructing right, obtuse, and acute musical triangles as well as projections of their edges (sides), which are recognized in trigonometry as the functions of angles: the sine, cosine, and so on; as well as the establishment of methods for constructing spectral and scalar (intonative-temporal) trigonometric unit circles with their function graphs.
\end{abstract}

Keywords: Aristoxenus of Tarentum, Johannes Kepler, lambdoma, micro-intervals, Pythagoras, planimetrics, rhythm, spectrum, trigonometry, triangle

Many years of research in the field of micro-intervals in the theory and practice of Middle Eastern and North African folk music as well as efforts to bring the language of mathematics closer to elementary musical tools such as rhythm,

\footnotetext{
* Author contact information: dragan8206@gmail.com
} 
metre, mode, and spectrum have yielded results in several publications: first, in my doctoral artistic project titled Primena mikrotonalnosti (a) $u$ instrumentalnoj blisko-istočnoj i balkanskoj muzici folklorne provenijencije, te (b) u instrumentalnoj, kamernoj $i$ orkestarskoj muzici akustičkog tipa u savremenoj zapadnoj umetničkoj muzici (pokušaj zasnivanja jedne autonomne stvaralačko-kompozitorske koncepcije (The Application of Micro-tonality (a) in Middle Eastern and Balkan Instrumental Folk Music and (b) in Western Acoustic Instrumental, Chamber, and Orchestral Music (An Attempt at Founding an Autonomous Creative-compositional Conception), 2014) and (2) Spektralna trigonometrija (zasnivanje univerzalne muzičko-matematičke analize (Spectral Trigonometry (Establishing a Universal Music-Mathematical Analysis) from 2017.

Thus posited, the discipline of mathematical music analysis rests on the assumption of a link between mathematics, specifically geometry on the one hand, and music on the other. Both studies mentioned above are based on the method of projecting individual harmonics of the spectrum. ${ }^{1}$

\section{The Projection Method}

The projection of intervals or chords is a procedure whereby one and the same elementary structure is retained, but its function is replaced. The vertical configuration of two different pitches (harmonic interval) or that of three or more different pitches (harmonic chord) is projected into the horizontal configuration of two different pitch lengths (projected interval) or that of three or more different pitch lengths (projected chord). Function replacement denotes the replacement of a harmonic ratio (identified by height determined by two points in space) by means of a projector into a new position - a position delineated by two points in time determined by the projected length, from which one may observe, define, and metrically calculate the propagation velocity of a given tonal ratio (or several of them). Therefore, a harmonic interval now comprises a unique relation: original pitch - projected length. The next step involves the establishment of a causal relation between three basic functions: pitch-length-velocity - a relation that, from the vertical perspective of harmony, already exists between any two harmonics in the spectrum. By means of function replacement, the newly acquired projected intervals and chords establish a new order in the system of proportions.

A projected harmonic octave, determined by the ratio between the second harmonic and the fundamental, would produce a rhythmic octave, constituted

\footnotetext{
${ }^{1}$ This concerns an abstract image of a projector that translates superimposed harmonics (the partials of an arbitrary fundamental) onto the metric-rhythmic plane. For more on the projector and the projection method, see the author's DMA dissertation, 115-122.
} 
by two equal rhythmic units. The projection method entails the differentiation of spectral space into four regions. The ratio between any individual harmonic and the fundamental is called absolute pitch. Only the second harmonic has absolute pitch only, in relation to the fundamental, and no relative pitch. The ratio between a higher and lower harmonic is called relative pitch. For instance, a relative pitch will take shape in the ratio between the third and second harmonic. Further, every harmonic contains a collection of intervals comprising all ratios between the higher and every lower harmonic (e.g. the relative pitches of the fifth harmonic: 5:4, 5:3, and 5:2), as well as in relation to the fundamental (the absolute pitch of the fifth harmonic: 5:1). In vertical projection, the octave intersects with the spectrum at even-numbered harmonics $(4: 2$ or $6: 3$ or $8: 4$ etc.), which means that all relative pitches that are less than half the value of the fundamental will always be on the so-called left side of the spectrum (e.g. the relative pitches of the fifth harmonic to the left: 5:4 and 5:3), starting from the third index number. Those relative pitches that exceed half the value of the fundamental will appear with the absolute pitch of each individual harmonic on the right-hand side of the spectrum (the relative and absolute pitches of the fifth harmonic on the right-hand side of the spectrum: 5:2 and 5:1). The relative pitch of the third harmonic is a perfect fifth $(3: 2)$, located on the left-hand side of the spectrum, while the absolute pitch of the third harmonic's collection of intervals is a perfect twelfth $(3: 1)$, located on the right-hand side of the spectrum. In the fourth harmonic's collection of intervals the relative pitch is a perfect fourth (4:3) on the left-hand side, while the absolute pitch is a perfect fifteenth $(4: 1)$ located on the right-hand side of the spectrum. The principle remains consistent further up and down the right- and left-hand side of higher harmonics.

Comparing the left- and right-hand sides of the spectrum is justified by further examination of metric progression and rhythmic sequencing by means of projecting collections of intervals from the referential systems of individual harmonics in the spectrum. On the left-hand side of the spectrum, projecting the ratio of any two harmonics will always yield an iamb, whereas on the right-hand side the result will always be a trochee. Both of them consist of projected intervals. In a metric ratio of 3:2 a rhythmic fifth is an iamb, whereas in a 3:1 ratio a rhythmic twelfth is a trochee. If we make a rhythmic crotchet (quarter-note) the fundamental of the spectrum and the basic measuring unit, an iamb would equal a triplet quaver (eighth-note) and a triplet crotchet $(1 / 3+2 / 3)$. In that regard, an iamb and trochee are measurable in thirds, because the longer part is twice longer than the short part. In a metric ratio of $4: 3$ a rhythmic fourth is likewise equivalent to an iamb, while in a $4: 1$ ratio a rhythmic double-octave is again equivalent to a trochee. Again, if we make a rhythmic crotchet the fundamental of the spectrum, an iamb will equal a rhythmic semiquaver (sixteenth-note) and 
a rhythmic dotted quaver $(1 / 4+3 / 4)$. An iamb and trochee would now be measurable in quarters, because the longer part would be three times longer than the shorter part.

The projection method is also applicable on the other side of the spectrum, which extends inversely, mirror-like, below the fundamental of the spectrum. This comprises the sub-harmonics, which are derived by means of the old Pythagorean procedure known as lambdoma, whereby the denominator and numerator of the fraction that constitute the value of a given harmonic in the higher region of the spectrum switch places; in concrete terms, producing the other, inversely proportional value of one and the same elementary structure. For the measuring ratio of a perfect fifth (3:2), from the perspective of the upper region of the spectrum, the sum of intervals equals $1 / 3+2 / 3$. For the measuring ratio of a perfect fifth $(3: 2)$ from the perspective of the lower region of the spectrum the ratio of intervals equals $1+2$. The basic metric segment in the projection of the second and third harmonic (1/3) is inversely proportional to metric length in the projection of the second and third sub-harmonics (3/1). For the measuring ratio of a perfect twelfth (3:1) from the perspective of the upper spectrum, the sum of intervals equals $(2 / 3+1 / 3)$. For the measuring ratio of a twelfth $(3: 1)$ from the perspective of the lower region of the spectrum the sum of intervals equals $(1+$ $1 / 2$ ). The basic metric segment in the projection of the third harmonic in relation to the fundamental $(2 / 3)$ is inversely proportional to the metric duration in the projection of the third sub-harmonic in relation to the fundamental $(3 / 2)$.

Therefore, the terms upper-left/right (1) and lower-left/right (2) serve to identify the spectral region of any given ratio between two harmonics or sub-harmonics. The principle remains the same throughout the right- and left-hand side of the upper harmonics and sub-harmonics.

\section{The Measuring of Spectral Angles and Triangles}

The German mathematician, astronomer, and astrologer Johannes Kepler, (1571-1630) "compared circles and strings and reasoned that consonant intervals are only those that stem from polygons that may be inscribed in a circle (using a ruler and compass). A string is shaped into a circle, the figure divides the circle into segments that one compares to one another to define intervals. The triangle thus corresponds to the interval of the fifth, because it divides the string by putting one segment into proportion with two segments or one segment into proportion with the entire string, which means the ratios of 2:3 and 1:3. On the basis of this proof, Kepler could claim that harmonic ratios stemmed from angular velocity (the size of the angle traversed by the planets around the Sun 
in a given amount of time), and not, as was constantly repeated since Antiquity, from linear distances and velocities". ${ }^{2}$

This proof by Kepler also underlies the measuring of the angles of spectral intervals on both sides of the lower and upper region of the spectrum. ${ }^{3}$ Musical notation is read and interpreted from left to right, in contrast to the quadrants of the Cartesian coordinate system. In a rhythmic projection, the octave as the second harmonic is (1) faster (equalling 1/2) or slower (equalling 2/1) than the velocity of the fundamental; and/or (2) shorter (equalling $1 / 2$ ) or longer (equalling 2/1) than the length of the fundamental. In this context, there will be two perspectives for one and the same phenomenon under observation - a phenomenon accommodating a change in the position of the second, or, in general terms, any harmonic in relation to the fundamental. Therefore, the fundamental is defined as the referential body, and the harmonic along with the fundamental (and its collection of intervals) as the referential system. Both the octave above and the octave below the fundamental constitute the coordinates that determine the trajectory whereby a given harmonic revolves around the fundamental; we may therefore conclude that the second harmonic, too, even though it has no collection of intervals that would allow us to differentiate between its relative and absolute pitch, still constitutes a referential system. From the first perspective, we might observe that the second harmonic revolves around its centre/fundamental and rotates around its axis faster (1/2) than the axial rotation of the fundamental (1/1), but revolves around the fundamental in a durational value twice as long $(2 / 1)$ as that with which we determine the proximity of the harmonic to the referential body. From the second perspective, we might observe that the same harmonic circles around its centre-fundamental and rotates around its axis more slowly $(2 / 1)$ than the axial rotation of the fundamental (1/1), but makes a full circle around the fundamental in a durational value two times smaller (1/2) than the value we use to determine the distance of the harmonic from the referential body.

If we compared the motion of the harmonic with that of a material point along a circle in the referential system of the second harmonic, bearing in mind that we took the $\pi$ geometrical constant to serve as the line segment of the fundamental, ${ }^{4}$ we might note that the radius vector of this point produces the following angles and angular displacements: $\Delta \theta:(1) \pi / 2 \mathrm{rad}$. corresponds to an angle of $90^{\circ}$ i.e. a convex (right) angle or the projected angle of a rhythmic quaver against a rhythmic quaver; (2) $\pi$ rad. corresponds to an angle of $180^{\circ}$ i.e. a straight angle,

\footnotetext{
${ }^{2}$ Filip Vendriks, Muzika u renesansi, Belgrade, Clio, 2005, 78.

${ }^{3}$ Dragan Latinčić, Mikrointervali u spektralnoj geometriji, Belgrade, Zadužbina Andrejević, 2015, 63-73.

${ }^{4}$ The value of the fundamental in this projection equals a rhythmic crotchet.
} 
that is, the line segment of the fundamental (which equals a rhythmic crotchet); (3) $3 \pi / 2$ rad. corresponds to an angle of $270^{\circ}$ i.e. a concave angle or the projected angle of a rhythmic minim (a rhythmic crotchet against a rhythmic crotchet).

If we compared the movement of a harmonic with that of a material point along a circle in the referential system of the third harmonic, we would observe that its radius vector outlines the following angles and produces the following angular displacements $\Delta \theta$ : (1) $\pi / 3 \mathrm{rad}$. corresponds to an angle of $60^{\circ}$ i.e. a convex (acute) angle that is the projected angle of a triplet quaver against a triplet crotchet; (2) $2 \pi / 3 \mathrm{rad}$. corresponds to an angle of $120^{\circ}$ i.e. a convex (obtuse) angle that is the projected angle of a triplet crotchet against a triplet quaver; (3) $4 \pi / 3 \mathrm{rad}$. corresponds to an angle of $240^{\circ}$ i.e. a concave angle that is the projected angle of a rhythmic crotchet against a rhythmic quaver; and (4) $5 \pi / 3 \mathrm{rad}$. corresponds to an angle of $300^{\circ}$ i.e. a concave angle that is the projected angle of a rhythmic crotchet against a rhythmic minim.

The first angular displacement is identified with the interval of the fifth in the upper region of the spectrum (3:2) as well as its metrical-rhythmic projection (which also applies to all other intervals of the spectrum). The perfect-fifth angle $\left(60^{\circ}\right)$ would correspond to one third of the length of an arc circumscribed around an equilateral triangle - which would equal $120^{\circ}$. This length would equal one third $\left(60^{\circ}\right)$ of the half-perimeter of the circle $\left(180^{\circ}\right)$. The second angular displacement is identified with the interval of a perfect twelfth in the upper region of the spectrum (3:1). The perfect-twelfth angle $\left(120^{\circ}\right)$ would correspond to two thirds of the length of the arc of a circle circumscribed around an equilateral triangle - which would equal $120^{\circ}$. This length would correspond to two thirds $\left(120^{\circ}\right)$ of the circle's half-perimeter. The third angular displacement $\left(240^{\circ}\right)$ is identified with the interval of a perfect twelfth in the lower region of the spectrum (3:1) as the difference between a full angle and the upper-spectrum perfect-twelfth angle $\left(360^{\circ}-120^{\circ}\right)$, and the fourth angular displacement $\left(300^{\circ}\right)$ is identified with the interval of a perfect fifth in the lower region of the spectrum (3:2) as the difference between a full angle and an upper-spectrum perfect-fifth angle $\left(360^{\circ}-60^{\circ}\right)$.

The unit circle of the spectrum would have to be assumed to be infinite. The reason is that there is an array of harmonics higher than the $16^{\text {th }}$ index number of the spectrum that are ramified in the same exponential progression as the lower ones. The circumference of the angles of upper-region spectral intervals is derived by having the diameter of the fundamental serve as the $\pi$ geometric constant.

This way, one may derive the angles of the following partial spectral intervals: minor third $\left(6: 5=30^{0}\right)$, major third $\left(5: 4=36^{0}\right)$, perfect fourth $\left(4: 3=45^{\circ}\right)$, 
perfect fifth $\left(3: 2=60^{\circ}\right)$, major sixth $\left(5: 3=72^{\circ}\right)$, octave $\left(2: 1=90^{\circ}\right)$, major tenth $\left(5: 2=108^{\circ}\right)$, perfect twelfth $\left(3: 1=120^{\circ}\right)$, double octave $\left(4: 1=135^{\circ}\right)$, major seventeenth $\left(5: 1=144^{\circ}\right)$, super-twelfth $\left(6: 1=150^{\circ}\right)$, and so on.

The circumference of the angles of spectral intervals in the lower region of the spectrum is performed counter-clockwise from the third quadrant. This way, one may derive the angles of the following spectral summation intervals: super-twelfth $\left(6: 1=210^{\circ}\right)$, major seventeenth $\left(5: 1=216^{\circ}\right)$, double octave $\left(4: 1=225^{\circ}\right)$, perfect twelfth $\left(3: 1=240^{\circ}\right)$, major tenth $\left(5: 2=252^{\circ}\right)$, octave $\left(2: 1=270^{\circ}\right)$, major sixth $\left(5: 3=288^{\circ}\right)$, perfect fifth $\left(3: 2=300^{\circ}\right)$, perfect fourth $\left(4: 3=315^{\circ}\right)$, major third $\left(5: 4=324^{\circ}\right)$, minor third $\left(6: 5=330^{\circ}\right)$, and so on.

A chord is the sum of two intervals. Projection generated two intervals only in the referential system of the third harmonic (two in the upper region of the spectrum: $1 / 3+2 / 3$ and $2 / 3+1 / 3$; and two in the lower region of the spectrum 1 +2 and $1+1 / 2$ ). If two interval ratios were superimposed in the projected interval constellations, this would produce a projected chord, in concrete terms, the rhythmic chord of the third harmonic. Therefore, superimposing the ratios that applied to the interval constellations of the collection of intervals of the third harmonic mentioned above, $(1 / 3+2 / 3)$ and $(2 / 3+1 / 3)$, would produce a unique relation: $(1 / 3+1 / 3+1 / 3)$. The projected chord now makes a planar triangle that would be equilateral in the referential system of the third harmonic (with equal angles): $60^{\circ}+60^{\circ}+60^{\circ}$. (Figure 1)

The respective relations between a higher harmonic and harmonics below it may be practically explained using the example of the three sides of a triangle. This would be a chordal triangle comprising three independently isolated frequencies originating from an arbitrarily chosen fundamental. These frequencies would constitute the intersections of metrical length - length that could be demonstrated by means of a projector, using mathematical formulations of metrical-rhythmic distances. The next task would concern the identification of both entities. The first entity would comprise three isolated frequencies, which would consist of the vertices of a planar triangle. The second entity would comprise the sides (edges) of the triangle as a metric length in the projection of a harmonic ratio. Both entities would thus come together in the geometric figure of a triangle with all of its planimetric and trigonometric characteristics.

This task also entails (1) establishing methods for constructing right, obtuse, and acute musical triangles as well as projections of the ratios between the sides, which is recognized in trigonometry as the angular function of these scalar triangles: the sine, cosine, and so on; as well as (2) the establishment of methods for constructing spectral and scalar (intonation-temporal) trigonometric circles with their function graphs. 


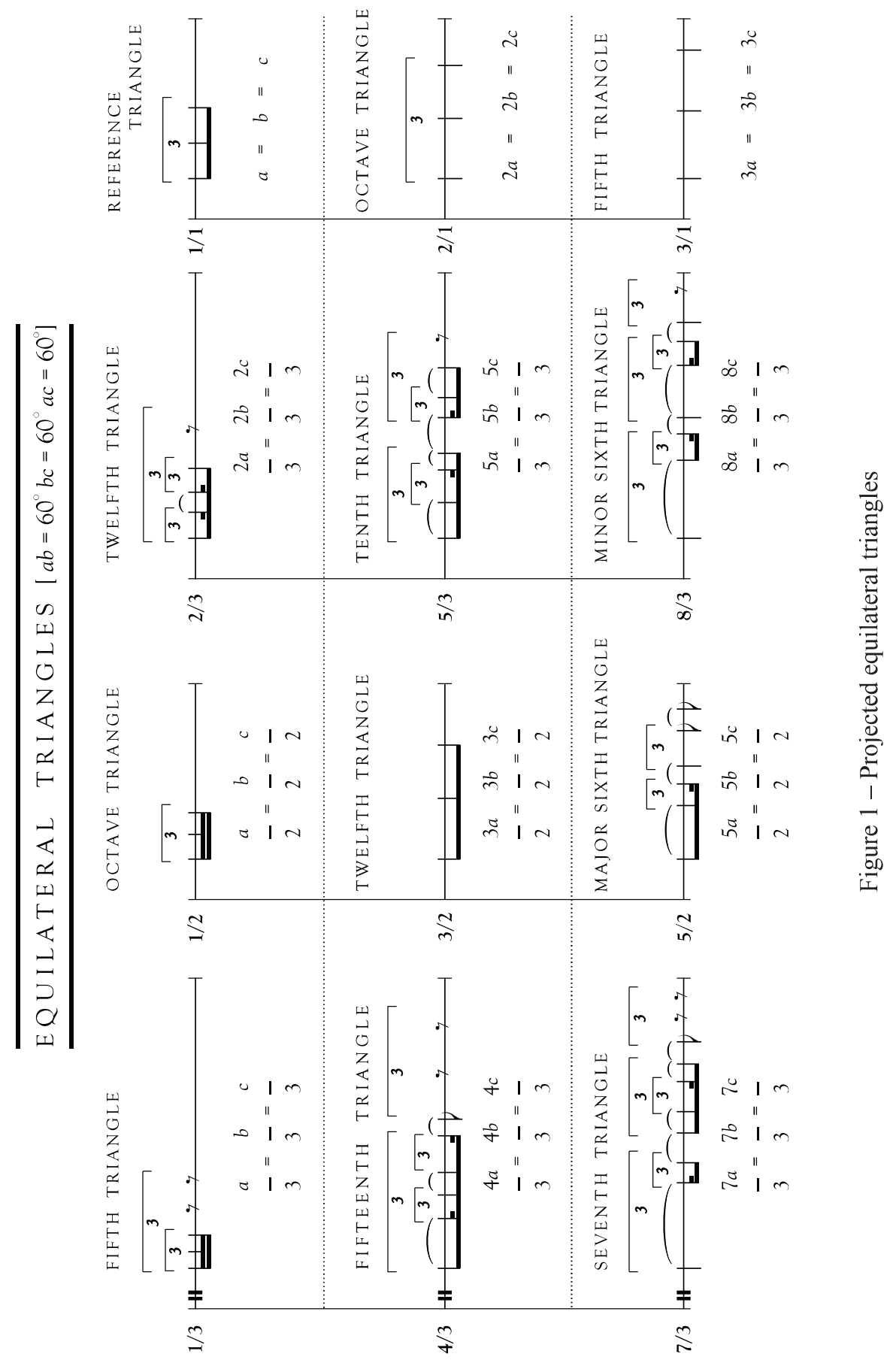




\section{Applying the Pythagorean Theorem to the Temporality of Rhythmic} Projections of Individual Harmonics in the Spectrum

Using the method of metric-rhythmic projection, it is possible to prove the applicability of the Pythagorean Theorem primarily with respect to the temporality of individual harmonics of the spectrum. The formulation derived would be applicable via the first Pythagorean triple (as well as all other Pythagorean triples), as follows: $(3 / x)^{2}+(4 / x)^{2}=(5 / x)^{2}$. The denominator serves to enable the recognition of the partials of the fundamental that pertain to the system of the given harmonic in the spectrum. If we took one sixth of a given individual relation as the numerator, that would mean that the quadrant of the described structure would be recognisable from the referential system of the sixth harmonic: $(3 / 6)^{2}$ $+(4 / 6)^{2}=(5 / 6)^{2}$. If we simplify the formulation to: $(1 / 2)^{2}+(2 / 3)^{2}=(5 / 6)^{2}$ we may see that the sum of squares constructed on the octave and the twelfth equals a square constructed on the super-twelfth. If we take a rhythmic crotchet as the fundamental of the spectrum, a triplet semiquaver could become the common denominator for squares constructed on the octave, twelfth, and super twelfth.

The "octave square" whose common multiple is a triplet semiquaver, which by means of the number 3 (the first number in the first Pythagorean triple) forms the adjacent side of the octave triangle, would equal nine triplet semiquavers. We may see that the octave square is a summation rhythmic twelfth $(3 / 2)-$ i.e. $\left(3^{2} \bullet\right.$ $1 / 6=3 / 2)$.

The "twelfth square", whose common multiple is likewise a triplet semiquaver, which by means of the number 4 (the second number in the first Pythagorean triple) forms the opposite side of the triangle of the twelfth, would equal 16 triplet semiquavers. We may see that a square on the twelfth is a summation minor sixth $(8 / 3)$ - i.e. $\left(4^{2} \cdot 1 / 6=8 / 3\right)$.

Finally, the "super-twelfth" square, whose common multiple again is a triplet semiquaver, which by means of the number 5 (the third number in the first Pythagorean triple) forms the hypotenuse of the super-twelfth triangle, would equal 25 triplet semiquavers. We may see that the super-twelfth square is a rhythmic semibreve (whole note) tied to a triplet semiquaver (25/6). (Figure 2)

Rhythmic factors are substituted by means of mathematical analysis of the trigonometric functions. Since this concerns a Pythagorean right triangle $|345|$, the angle formed by the octave and twelfth sides is $90^{\circ}$, the angle formed by the twelfth side and super-twelfth hypotenuse acquires a new value in relation to the value of the minor-third referential angle $\left(30^{\circ}\right)$ and equals $\theta=30^{\circ}+6^{0} 52^{\prime} 12^{\prime \prime}$, while the angle formed by the super-twelfth hypotenuse and octave side acquires a new value in relation to the value of the perfect-fifth referential angle $\left(60^{\circ}\right)$ and equals the remaining $60^{0}-6^{0} 52^{\prime} 12^{\prime}$ ". The trigonometric functions of the acute angle $\left(\theta=36^{0} 52^{\prime} 12^{\prime \prime}\right)$ of a right triangle with its sides forming the first Pythagorean triple are determined as follows. 


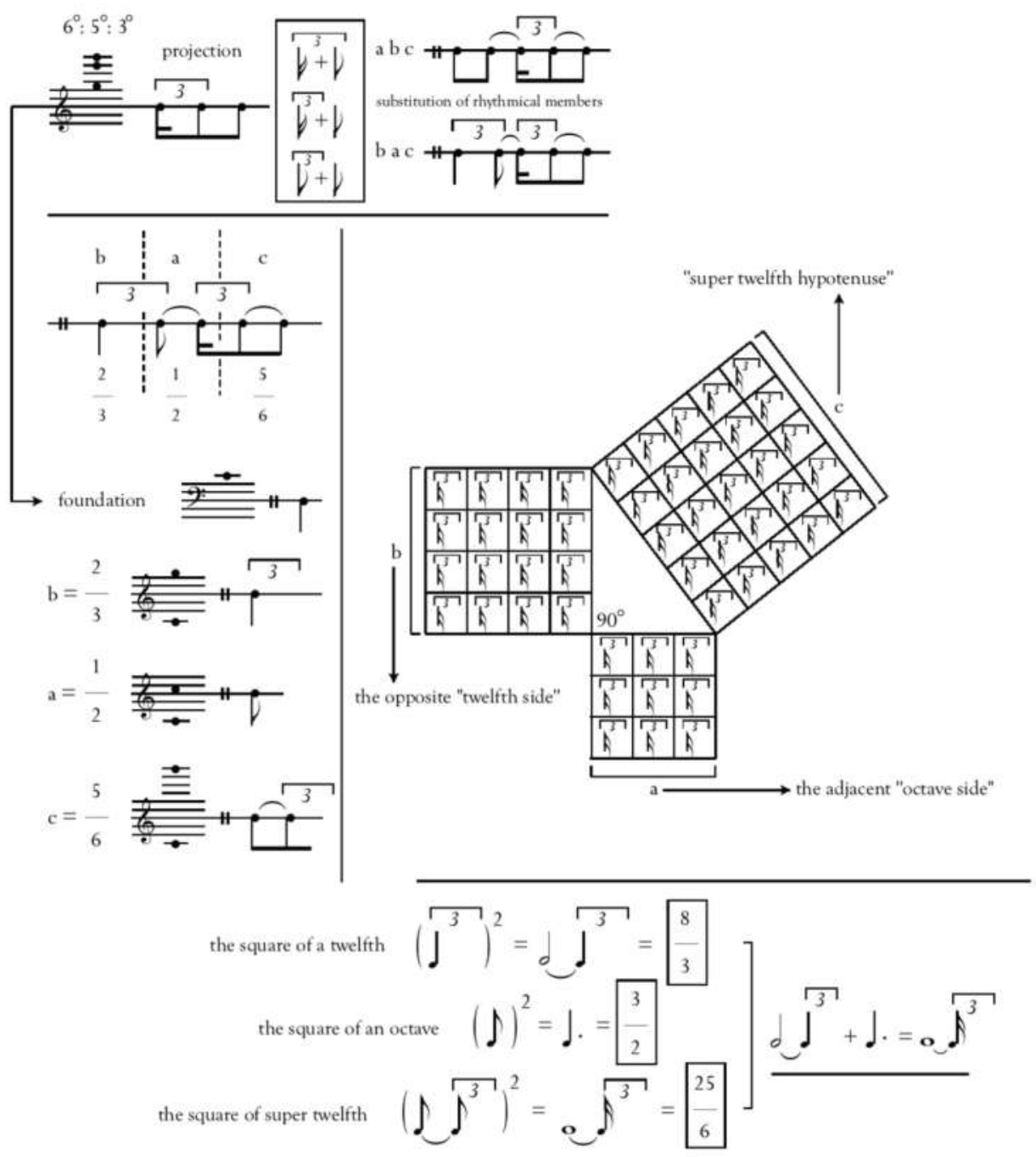

Figure 2 - Applying the Pythagorean Theorem on the right angle of the sixth harmonic of the spectrum

The sine of the angle $-\sin \theta$ is the ratio between the opposite side and the hypotenuse, more precisely, the quotient of an octave and a super twelfth or $[(1 / 2) /(5 / 6)]$. The quotient of these two fractions is $3 / 5$.

The cosine of the angle $-\cos \theta$ is the ratio between the adjacent side and the hypotenuse, more precisely, the quotient of a twelfth and a super-twelfth or $[(2 / 3) /(5 / 6)]$. The quotient of these two fractions is $4 / 5$. 
The tangent of the angle $-\tan \theta$ is the ratio between the opposite and adjacent sides, more precisely, the quotient of an octave and a twelfth or $[(1 / 2) /$ $(2 / 3)$ ]. The quotient of these two fractions is $3 / 4$.

The cotangent of the angle $-\cot \theta$ is the ratio between the adjacent and opposite sides, more precisely, the quotient of a twelfth and an octave or $[(2 / 3) /$ $(1 / 2)]$. The quotient of these two fractions is $4 / 3$.

The secant of the angle $-\sec \theta$ is the ratio between the hypotenuse and adjacent side, more precisely, the quotient of a super twelfth and twelfth or [(5/6)/ $(2 / 3)]$. The quotient of these two fractions is $5 / 4$.

The cosecant of the angle $-\csc \theta$ is the ratio between the hypotenuse and the opposite side (edge), more precisely, the quotient of a super twelfth and an octave, $[(5 / 6) /(1 / 2)]$. The quotient of these two fractions is $5 / 3$.

The ratio between the intervals of the collection of intervals of the sixth harmonic in the spectrum, comprising the octave (6:3), twelfth (6:2), and super twelfth (6:1), established via the Pythagorean Theorem, which can be expressed with the following mathematical relation: $(1 / 2)^{2}+(2 / 3)^{2}=(5 / 6)^{2}$, may now be applied, following the same principle, to the collections of intervals of other individual harmonics in the spectrum. From among several examples, we will look at one more.

If we take one fourth of a given individual ratio between two harmonics as our denominator that would mean that the square of that structure would be recognisable from the referential system of the fourth harmonic: $(3 / 4)^{2}+(4 / 4)^{2}$ $=(5 / 4)^{2}$. If we take one rhythmic crotchet as our measuring unit (1), via the first Pythagorean triple $|345|$, a rhythmic crotchet is multiplied by means of the Pythagorean Theorem, which adheres to the following rule: $\mathrm{a}^{2}+\mathrm{b}^{2}=\mathrm{c}^{2}$, in the following way: $(3 \times \text { one rhythmic semiquaver })^{2}+(4 \times \text { one rhythmic semiquaver })^{2}$ $=(5 \times \text { one rhythmic semiquaver })^{2}$.

It follows that the sum of a squared dotted rhythmic quaver and a squared rhythmic crotchet equals the square of a rhythmic crotchet tied to a rhythmic semiquaver. The mathematical formula of the first Pythagorean triple: $3^{2}+4^{2}=$ $5^{2}$ in the referential system of the fourth harmonic (which would apply to a perfect fourth) is equivalent to: $(3 / 4)^{2}+1^{2}=(5 / 4)^{2}$.

This formulation is identical to that found in an ancient Egyptian papyrus discovered at Kahun, from around 2000 BC. Among other things, this papyrus, dated to the time of Egypt's $12^{\text {th }}$ dynasty, mentions the relation linked above to the referential system of the fourth harmonic of the spectrum, by applying the Pythagorean Theorem: $1^{2}+(3 / 4)^{2}=\left(1 \frac{1}{4}\right)^{2}$ : "The Egyptians also knew the numerical relation for special cases, for a papyrus of the 12th dynasty (c. 2000 B. C.), discovered at Kahun, refers to four of these relations, one being $1^{2}+(3 / 4)^{2}$ 
$=\left(1 \frac{1}{4}\right)^{2}$. It was among these people that we first hear of the 'rope stretchers', those surveyors who, it is usually thought, were able by the aid of this property to stretch a rope so as to draw a line perpendicular to another line, a method still in use at the present time". ${ }^{5}$ (Figure 3)

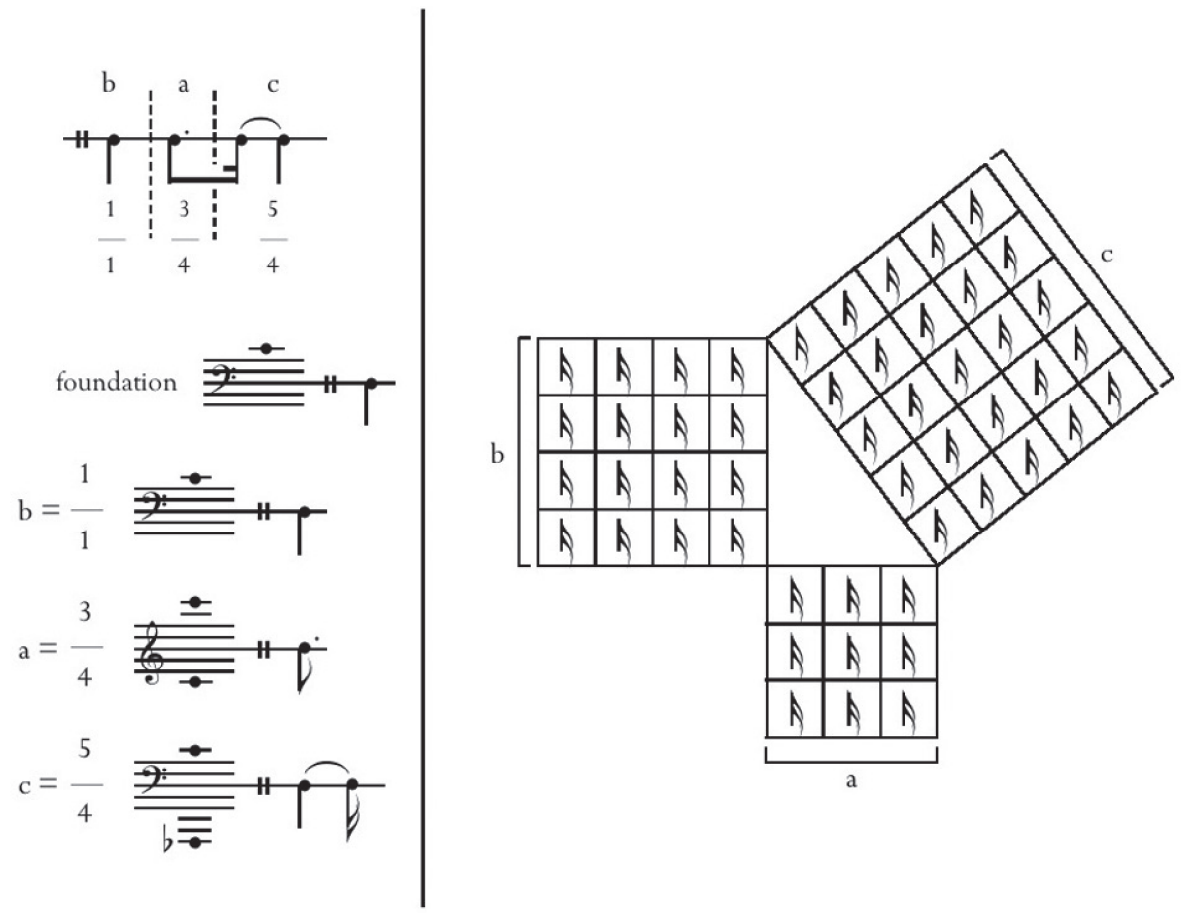

Figure 3 - Applying the Pythagorean Theorem to the perfect-fourth triangle of the fourth harmonic of the spectrum

By analogy to the first Pythagorean Theorem, we may now construct spectral triangles from higher triples, which are likewise governed by the Pythagorean Theorem. The principle is the same. Choosing a projected rhythmic interval as the measuring unit and a higher triple enables the analysis of new interval side lengths, as well as the intersections of those triangle sides (edges) at new angles.

${ }^{5}$ D. E. Smith, History of Mathematics (Volume II). Special Topics of Elementary Mathematics, Boston, Ginn and Company, 1, 1925, 288. 


\section{Isometric Transformations of Spectral Triangles}

Relations applicable to the spectrum may be consistently transformed into the scalar and temporal system. So far, we have observed spectral geometric entities on the basis of projections of metric-rhythmic structures. We will now perform the process of transforming the newly acquired geometric entities (primarily triangles) into a system of musical scales. Using Aristoxenus's equivalence of distance and height, we may observe that the Pythagorean Theorem applies to scale intervals (chords) as well. Observing Aristoxenus's ('A vision of the octave into six equal whole tones and 12 semitones, we may draw an analogy with the sharpening of scale resolution in the following way: we would divide the octave scale within the referential system of the third harmonic of the spectrum into 18 equal segments - third-tones, while the scale within the referential system of the fourth harmonic in the spectrum would be divided into 24 equal segments - quarter-tones. ${ }^{6}$

Transformation is a function whereby individual points are mapped onto some other points. The type of transformation that preserves the same distances and angles is called isometric transformation. Isometric transformation of projected metric lengths of original harmonics is a function that maps individual spectral frequencies as intonation points (retreats) within an arbitrarily chosen musical scale. Regarding this transformation, one should note that the intonation points of retreat match the polygonal line of the spectral metric-rhythmic projection. A series of three (intonative-temporal) line segments are linked together. The process of isometric transformation unfolds in several different stages.

In the first stage, the first Pythagorean triple $|345|$ is isolated. Then, further triples are generated on the basis of the first, original triple, by multiplying it with the number of each harmonic (from the second to the $\left.16^{\text {th }}\right)$, for instance: $\mid(3 \times 2)$ $(4 \times 2)(5 \times 2) \mid$ which equals $|6810|$ or $|(3 \times 3)(4 \times 3)(5 \times 3)|$ which is $|91215|$ and so on. In the second stage, the numbers of the first Pythagorean triple $|345|$ and those of the following triples derived from it, $\left|\begin{array}{ll}6 & 810 \mid\end{array}\right| 91215 \mid$, are divided by their common denominator, which is also the number of the harmonic. This denominator sharpens scalar (intonative) resolution $(6 / 3,8 / 3$, and $10 / 3)$. In the third stage, scale values may be defined by distance from the next pitch (that is, the pitch of an individual point in the scale triangle). The pitches successively

\footnotetext{
${ }^{6}$ Only in theory, one cannot exclude an even finer fragmentation of intonative resolution, which means that the octave scale of the fifth harmonic could be divided into 30 equal fifthtones and that of the sixth harmonic into 36 equal sixth-tones. This is mentioned here on the assumption that intonative displacements of this kind of sophistication may be found in Middle Eastern and North African folk music.
} 
stack up the farther we get from their common multiple (fundamental), which suggests that each new pitch becomes the starting (zero-) point in relation to the preceding one.

The superiority of this type of transformation, which is performed by juxtaposing pitches, is reflected in the fact that it offers the multiple possibility of constructing a triangle with the same ratios between its sides, substituting the rhythmic and intonative factors in the planimetry. The superiority of this type of transformation is also reflected in that the vertices of an isosceles triangle or the vertices of an equilateral triangle are distinguished by different intonation distances. (Figure 4)

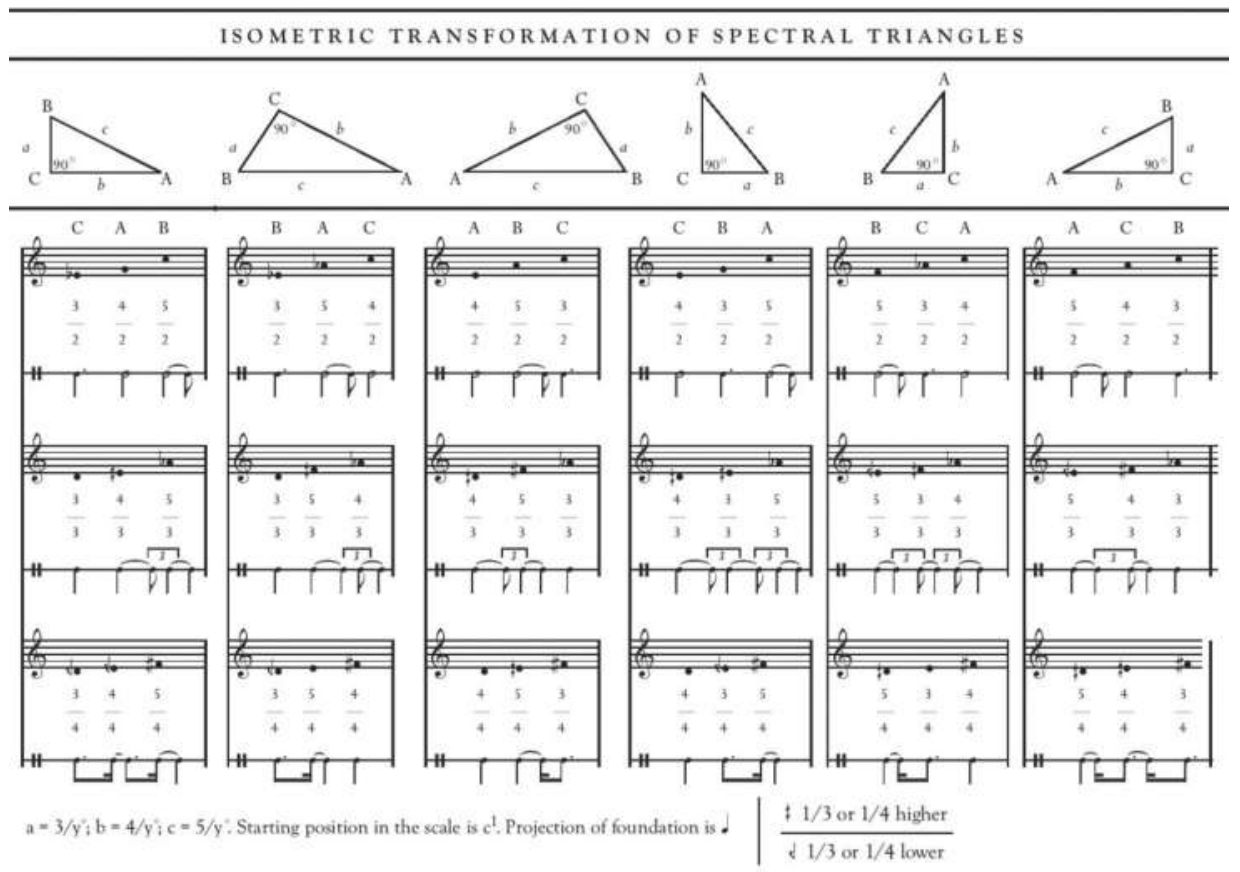

Figure 4 - Isometric transformations of spectral triangles

This is a good place to remember some words by the Serbian musicologist Dragutin Gostuški and link the example of isometric transformation of a temporal-intonation triangle with the ratio between the numbers 3,4 , and 5 , used by ancient Greek instrument builders to tie the strings of a lyre.

One cannot even ask the question whether and to what degree the mathematical analogy between the figural and the musical is justified before answering the question about the cause of matching between a physical phenomenon and elementary 
relations among natural numbers. For, we may agree with Crocker that the fact that 3,4 , and 5, that is, the only numbers that lend the Pythagorean Theorem a rational solution, simultaneously match the ratios of the Egyptian 'holy triangle', the principle that ancient Greek instrument builders used to tie the strings on the lyre, and the frequency ratio of the European major chord is a 'tautology'. We may therefore say that musical intervals were chosen according to numeric ratios and not that those ratios were later discovered. However, the question of harmonics does not yield to choice; and the question lies therein. A satisfactory answer has yet to be found. ${ }^{7}$

In Figure 4, the sixth example in the first row shows the juxtaposition of the temporal distances of a right triangle $(c=5 / 2 ; b=4 / 2 ; a=3 / 2)$, causing a displacement of the frequencies (the vertices of this triangle) according to the following configuration: $\left(A=\mathrm{f}^{1} ; C=\mathrm{a}^{1} ; B=\mathrm{c}^{2}\right)$. Since this is a right triangle, the orthocentre of this scale triangle would be its altitude (height), $\mathrm{c}^{2}$. If we make $\mathrm{c}^{1}$ the starting position of the scale, isometric transformation will produce a sonority comprising $\mathrm{f}^{1}$ - a perfect fourth (the fourth harmonic) from the starting position, $\mathrm{a}^{1}-\mathrm{a}$ major third (the fifth harmonic) from the starting position of $\mathrm{f}^{1}$, and $c^{2}-a$ minor third (the sixth harmonic) from the frequency of $a^{1}$, therefore $6: 5: 4$, which is recognized in European music theory precisely as the European major triad. This is yet another reason why it is important to observe the principle of isometric transformation by means of juxtaposing frequencies.

The procedure of isometric transformation proves the applicability of the Pythagorean as well as many other theorems in trigonometry, such as the sine, cosine, and tangent theorems, as well as Mollweide's formula. My book Spektralna trigonometrija (zasnivanje univerzalne muzičko-matematičke analize) offers insight into the method of constructing musical figures (triangles) with concise and minute mathematical derivatives and formulae. The procedure of isometric transformation opens the possibility of constructing right, acute, and obtuse angles within musical scales with all the accompanying planimetric and trigonometric characteristics. ${ }^{8}$

\section{Applying the Trigonometric Functions to the Scalar Musical Plane}

The sine is a curve; in music, a glissando could be used to describe a curve. If the sine curve of a glissando rises and falls in the first and second quadrant, the glissando will rise and fall above the horizon of the fundamental. If the sine falls

\footnotetext{
${ }^{7}$ Dragutin Gostuški, Vreme umetnosti: Prilog zasnivanju jedne opšte nauke o oblicima, Belgrade, Prosveta, 1968, 242.

${ }^{8}$ Dragan Latinčić, Spektralna trigonometrija (zasnivanje univerzalne muzičko-matematičke analize), Belgrade, Zadužbina Andrejević, 2017, 119-132.
} 
and rises in the third and fourth quadrants, the glissando will fall and then rise beneath the horizon of the fundamental. The sine accommodates all values from one whole step (a major second) above the starting position in the interval [0, $\pi]$ for the first two quadrants as well as all values from one whole step (a major second) above the starting position in the interval $[\pi, 2 \pi]$ for the other two quadrants. If we take the horizon of the fundamental as the starting position of the scale, for instance, $\mathrm{c}^{1}$, we may determine the sine function co-domain $[1,-1]$. It would equal the scale value of a major third $\left[1=\mathrm{d}^{1},-1=b\right]$. If the sine accommodates values up to a whole degree for each quadrant, that would mean that a half-step would equal $30^{\circ}$ on the sine graph.

The formula for calculating the sine intonation retreat point in a trigonometric unit circle whose co-domain is a major third is the product of the desired frequency and the sixth root of 2 (because the octave is divided into six equal parts) raised to the power of the sine of the chosen interval angle.

For instance, for the frequency of $\mathrm{c}^{1}(261.63 \mathrm{~Hz})$ the corresponding value will be $261.63 \times \sqrt[6]{2} \sin 90=293.66 \mathrm{~Hz}$, which equals one distance $\left(\mathrm{d}^{1}\right)$ of the scale sine from the starting frequency $\left(\mathrm{c}^{1}\right)$; or, $261.63 \times \sqrt[6]{2}^{\sin 30}=277.18 \mathrm{~Hz}$, which is $1 / 2$ of the distance $\left(\mathrm{c} \operatorname{sharp}^{1}\right)$ from the starting frequency $\left(\mathrm{c}^{1)}\right.$; or, $261.63 \times \sqrt[6]{2}^{\sin 14.4775}=269.29 \mathrm{~Hz}$, which is $1 / 4$ of the distance $\left(c^{1}+1 / 4\right)$ from the starting frequency $\left(\mathrm{c}^{1}\right)$, and so on.

The sine relations in each quadrant are verified with the formula for calculating the sine intonation retreat point. To verify a quarter of the distance above the starting scale position $\left(c^{1}+1 / 4\right.$ for the frequency of $\left.c^{1}=261.63 \mathrm{~Hz}\right)$, from the first and second quadrants, the following comparison is used:

$261.63 \times \sqrt[6]{2}^{\sin 14.4775}=261.63 \times \sqrt[6]{2} \sqrt{2}^{\sin 165.5225}=269.29 \mathrm{~Hz}$.

It is similar with calculating one half of the distance $\left(\mathrm{c}\right.$-sharp $\left.{ }^{1}\right)$ from the frequency of $c^{1}: 261.63 \times \sqrt[6]{2} \sqrt{\sin 30}^{\sin }=261.63 \times \sqrt[6]{2}{ }^{\sin 150}=277.18 \mathrm{~Hz}$.

In general, the formula for any intonation trigonometric retreat in a trigonometric unit circle would be as follows: $f \times \sqrt[6]{2}^{\sin |\cos | \tan |\cot | \sec \mid \csc }$ with $f$ denoting frequency in $\mathrm{Hz}$ and $\sqrt[6]{2}$ the power base of the unit circle with whose co-domain is a major third whence the intonation trigonometric retreat is performed, while the power of exponentiation would be a trigonometric function of the angles.

For the sine function, all intervals in the third and fourth quadrants, below the horizon of the fundamental, have a negative prefix, i.e. have a negative distance in relation to the starting scale position. 
A glissando could also be formulated with the cosine - sliding from one pitch to another. If its cosine curve falls in the first and then also in the second quadrant, the glissando will fall above and then also below the horizon of the fundamental. If the cosine curve rises in the third and then also in the fourth quadrant, the glissando will rise below and then also above the horizon of the fundamental. We may note that the cosine accommodates all values from two whole steps (a major third) above the starting position in the interval $[0, \pi]$ for the first two quadrants and likewise all values from two whole steps (a major third) below the starting position in the interval $[\pi, 2 \pi]$ for the other two quadrants. We may therefore conclude that the cosine co-domain is the same as it was for the sine function: a major third.

The formula for calculating the cosine intonation retreat in a trigonometric unit circle whose co-domain is a major third is the product of the desired frequency and the sixth root of 2 (because the octave is divided into six equal parts) raised to the power of the cosine of the chosen interval angle.

For instance, for the frequency of $\mathrm{c}^{1}(261.63 \mathrm{~Hz})$ the corresponding value will be $\backslash 261.63 \times \sqrt[6]{2}=293.66 \mathrm{~Hz}$, which equals one distance $\left(\mathrm{d}^{1}\right)$ from the starting frequency $\mathrm{c}^{1}$; or, $261.63 \times \sqrt[6]{2}^{\cos 60}=277.18 \mathrm{~Hz}$, which is $1 / 2$ of the distance $\left(\mathrm{c}\right.$-sharp $\left.{ }^{1}\right)$ from the starting frequency c $\mathrm{c}^{1}$; or, $261.63 \times \sqrt[6]{2}^{\cos 75.5225}=269.29$ $\mathrm{Hz}$, which equals $1 / 4$ of the distance $\left(\mathrm{c}^{1}+1 / 4\right)$ from the starting frequency of $\mathrm{c}^{1}$, and so forth.

The cosine relations in each quadrant may be verified with the formula for calculating the cosine intonation retreat. Given that the cosine is negative in the second and third quadrants, we may verify one quarter-distance below the starting scale position (for example, $c^{1}-1 / 4$ for the frequency of $c^{1}=261.63 \mathrm{~Hz}$ ), from the second and third quadrant as follows:

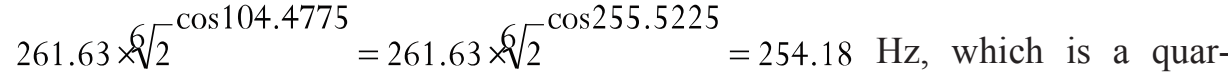
ter-tone lower $\left(c^{1}-1 / 4\right)$ than the pitch height of $\mathrm{c}^{1}$.

It is similar with a half-distance (b) from the frequency of $\mathrm{c}^{1}$ :

$261.63 \times \sqrt[6]{2}^{\cos 120}=261.63 \times \sqrt[6]{2}^{\cos 240}=246.94 \mathrm{~Hz}$, which is a semitone lower (b) than the pitch height of $\mathrm{c}^{1}$.

We may note that all intervals in the second and third quadrants below the horizon of the fundamental have a negative prefix, i.e. have a negative distance from the starting scale position. Negative intervals are marked only when analysing the trigonometric functions, in order to make clear the negativity of the function. 
The formula for calculating the tangent intonation retreat in a trigonometric unit circle whose co-domain is a major third is the product of the desired frequency and the sixth root of 2 (because the octave is divided into six equal parts) raised to the power of the tangent of the chosen interval angle.

For instance, for the frequency of $\mathrm{c}^{1}(261.63 \mathrm{~Hz})$ the corresponding value will be $261.63 \times \sqrt[6]{2}^{\tan 45}=293.66 \mathrm{~Hz}$. A frequency of $293.66 \mathrm{~Hz}$ is $\left(\mathrm{d}^{1}\right)$, that is, one distance above the starting frequency of $\mathrm{c}^{1}$. Therefore, we may note that one whole distance (a whole step) below the starting frequency of $\mathrm{c}^{1}(261.63 \mathrm{~Hz})$

will be $261.63 \times \sqrt[6]{2}^{\tan 135}=233.08 \mathrm{~Hz}$. A frequency of $233.08 \mathrm{~Hz}$ is (b flat), that is, one distance below the starting frequency of $\mathrm{c}^{1}$.

The procedures and formulations described above bring us to the phenomenon of trigonometric counterpoint, where one and the same frequency (for instance, the intonation distance - which is one step) would equal the sine, cosine, and tangent retreat, at different angles, of course. We may observe that for one whole scale degree above the diameter of the fundamental $\left(d^{1}=293.66 \mathrm{~Hz}\right)$ the corresponding value is:

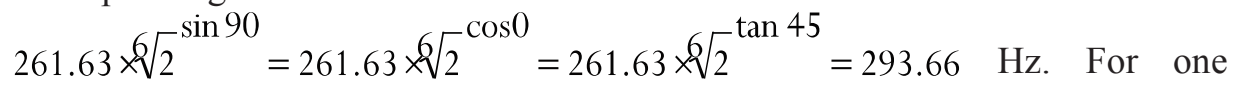
whole scale degree below the diameter of the fundamental $(b$ flat $=233.08 \mathrm{~Hz})$ the corresponding value is:

$261.63 \times \sqrt[6]{2}^{\sin 270}=261.63 \times \sqrt[6]{2}{ }^{\cos 180}=261.63 \times \sqrt[6]{2}{ }^{\tan 135}=233.08 \mathrm{~Hz}$.

In the construction of a musical trigonometric circle, we observed that the sine and cosine curves were governed by their function co-domain. If the sine and cosine co-domain was $[-1,1]$, sharpening a scale resolution to one sixth of a scale degree, we concluded that this co-domain equalled a major third, that is, that the entire unit circle belonged to the referential system of the fifth harmonic of the spectrum, because the major third is the referential interval for the referential system of this harmonic. Let us briefly consider a trigonometric circle whose amplitude $[-\mathrm{a}, \mathrm{a}]$ for the scale sine as well as the cosine graph would equal an octave.

If the sine and cosine amplitude equals $[-3,3]$, sharpening the scale resolution to one sixth of a scale degree, we will conclude that it spans an octave, that is, that the entire unit circle belongs to the referential system of the second harmonic of the spectrum. We come to this phenomenon by replacing the exponentiation base with the trigonometric intonation retreat. If the base for a trigonometric unit circle previously equalled $\sqrt[6]{2}$, for an amplitude spanning an octave it will now equal $\sqrt{2}$. This would be the basis for an octave trigonometric circle. 
In general, we may derive an array of trigonometric circles by changing the exponentiation base that serves to expand (amplitude-wise) the interval diameter (or radius). For example, let us take the tangents of $45^{\circ}$ and $135^{\circ}$ because their arguments are +1 and -1 , which correspond to the values of the radius of a trigonometric unit circle at the tangent. Thus the diameter of the unit circle (b-flat $\left.\mathrm{d}^{1}\right)$, that is, its radii are: $[0,+1]=\left(\mathrm{c}^{1}, \mathrm{~d}^{1}\right)$ and $[0,-1]=\left(\mathrm{c}^{1}, \mathrm{~b}\right.$-flat $)$. See the table.

Table of trigonometric unit circles (the tangent of the first and second quadrants)

\begin{tabular}{|c|c|c|c|c|}
\hline $\begin{array}{l}\text { Scalar } \\
\text { trigonometric } \\
\text { circles }\end{array}$ & \multicolumn{2}{|c|}{$\begin{array}{l}\text { Formulae for calculating trig- } \\
\text { onometric intonation retreat } \\
\text { points }\end{array}$} & $\begin{array}{c}\text { Value of the } \\
\text { trigonometric } \\
\text { retreat point } \\
\text { for } \mathrm{c}^{1}=\mathbf{2 6 1 . 6 3} \\
\mathrm{Hz} \\
\end{array}$ & $\begin{array}{l}\text { diameter and } \\
\text { radius of scalar } \\
\text { circle }\end{array}$ \\
\hline \multirow{2}{*}{$\begin{array}{l}1 / 2 \text { step - major- } \\
\text { second circle }\end{array}$} & \multirow{2}{*}{$261.63 \mathrm{~Hz}$} & $12 \sqrt{2}^{\tan 45}$ & $277.18 \mathrm{~Hz}$ & c-sharp ${ }^{1}$ \\
\hline & & $\cdot \sqrt[12]{2} \sqrt{\tan 135}^{-13}$ & $246.94 \mathrm{~Hz}$ & $\mathrm{~b}$ \\
\hline \multirow{2}{*}{$\begin{array}{l}\text { whole step - major- } \\
\text { third unit circle }\end{array}$} & \multirow{2}{*}{$261.63 \mathrm{~Hz}$} & $\sqrt[6]{2}{ }^{\tan 45}$ & $293.66 \mathrm{~Hz}$ & $\mathrm{~d}^{1}$ \\
\hline & & $\sqrt[6]{2}{ }^{\tan 135}$ & $233.08 \mathrm{~Hz}$ & $\mathrm{~b}$ flat \\
\hline \multirow{2}{*}{$\begin{array}{l}3 / 2 \text { step - } \\
\text { augmented-fourth } \\
\text { circle }\end{array}$} & \multirow[b]{2}{*}{$261.63 \mathrm{~Hz}$} & $\sqrt[4]{2^{\tan 45}}$ & $311.13 \mathrm{~Hz}$ & d-sharp ${ }^{1} \sim$ e-flat ${ }^{1}$ \\
\hline & & $\cdot \sqrt[4]{2}{ }^{\tan 135}$ & $220.00 \mathrm{~Hz}$ & $\mathrm{a}$ \\
\hline \multirow{2}{*}{$\begin{array}{l}2 \text { steps - minor- } \\
\quad \text { sixth circle }\end{array}$} & \multirow{2}{*}{$261.63 \mathrm{~Hz}$} & $\sqrt[3]{2} \sqrt{\tan 45}^{-}$ & $329.63 \mathrm{~Hz}$ & $\mathrm{e}^{1}$ \\
\hline & & $\cdot \sqrt[3]{2}^{\tan 135}$ & $207.65 \mathrm{~Hz}$ & g-sharp a-flat \\
\hline \multirow{2}{*}{$\begin{array}{l}5 / 2 \text { steps - minor- } \\
\text { seventh circle }\end{array}$} & \multirow{2}{*}{$261.63 \mathrm{~Hz}$} & $12 \sqrt[2]{2}^{5 \tan 45}$ & $349.23 \mathrm{~Hz}$ & $\mathrm{f}^{1}$ \\
\hline & & $\cdot \sqrt[12]{2^{5 \tan 135}}$ & $196.00 \mathrm{~Hz}$ & $\mathrm{~g}$ \\
\hline \multirow[b]{2}{*}{$\begin{array}{l}3 \text { steps - octave } \\
\text { circle }\end{array}$} & \multirow[b]{2}{*}{$261.63 \mathrm{~Hz}$} & $\sqrt{2}^{\tan 45}$ & $370.00 \mathrm{~Hz}$ & f-sharp ${ }^{1}$ \\
\hline & & $\cdot \sqrt{2}^{\tan 135}$ & $185.00 \mathrm{~Hz}$ & f sharp \\
\hline
\end{tabular}




\begin{tabular}{|c|c|c|c|c|}
\hline \multirow{2}{*}{$\begin{array}{l}\text { 7/2 steps - major- } \\
\text { ninth circle }\end{array}$} & \multirow{2}{*}{$261.63 \mathrm{~Hz}$} & $\cdot \sqrt[12]{2}{ }^{7 \tan 45}$ & $392.00 \mathrm{~Hz}$ & $\mathrm{~g}^{1}$ \\
\hline & & $\cdot \sqrt[12]{2}{ }^{7 \tan 135}$ & $174.61 \mathrm{~Hz}$ & $\mathrm{f}$ \\
\hline \multirow{2}{*}{$\begin{array}{l}4 \text { steps - major- } \\
\text { tenth circle }\end{array}$} & \multirow{2}{*}{$261.63 \mathrm{~Hz}$} & $\cdot \sqrt[3]{2^{2 \tan 45}}$ & $415.31 \mathrm{~Hz}$ & a-flat ${ }^{1} \sim$ g-sharp ${ }^{1}$ \\
\hline & & $\cdot \sqrt[3]{2^{2 \tan 135}}$ & $164.81 \mathrm{~Hz}$ & e \\
\hline \multirow{2}{*}{$\begin{array}{c}9 / 2 \text { steps }- \\
\text { augmented-eleventh } \\
\text { circle }\end{array}$} & \multirow{2}{*}{$261.63 \mathrm{~Hz}$} & $\sqrt[4]{2}{ }^{3 \tan 45}$ & $440.00 \mathrm{~Hz}$ & $a^{1}$ \\
\hline & & $\cdot \sqrt[4]{2^{3 \tan 135}}$ & $155.56 \mathrm{~Hz}$ & e flat \\
\hline \multirow{2}{*}{$\begin{array}{l}5 \text { steps - minor- } \\
\text { twelfth circle }\end{array}$} & \multirow{2}{*}{$261.63 \mathrm{~Hz}$} & $\sqrt[6]{2}{ }^{5 \tan 45}$ & $466.17 \mathrm{~Hz}$ & b-flat ${ }^{1}$ \\
\hline & & $\sqrt[6]{2}{ }^{5 \tan 135}$ & $146.83 \mathrm{~Hz}$ & $\mathrm{~d}$ \\
\hline \multirow{2}{*}{$\begin{array}{c}11 / 2 \text { steps }- \\
\text { augmented-twelfth } \\
\text { circle }\end{array}$} & \multirow{2}{*}{$261.63 \mathrm{~Hz}$} & $12 \sqrt{2}^{11 \tan 45}$ & $493.89 \mathrm{~Hz}$ & $b^{1}$ \\
\hline & & $\cdot \sqrt[12]{2^{11 \tan 135}}$ & $138.59 \mathrm{~Hz}$ & $\mathrm{~d}$ flat \\
\hline \multirow{2}{*}{$\begin{array}{l}6 \text { steps - double- } \\
\text { octave circle }\end{array}$} & \multirow{2}{*}{$261.63 \mathrm{~Hz}$} & $2^{\tan 45}$ & $523.26 \mathrm{~Hz}$ & $\mathrm{c}^{2}$ \\
\hline & & $\cdot 2^{\tan 135}$ & $130.81 \mathrm{~Hz}$ & $\mathrm{c}$ \\
\hline
\end{tabular}

\section{Conclusion}

Mathematical music analysis constitutes only the beginning of research in spectral intervallic and spectral chordal relations through the language of mathematics (geometry, planimetrics, and trigonometry). I have also applied the method of projecting harmonics as well as the principles of constructing planar geometric figures (primarily triangles) in my work as a composer. ${ }^{9}$ Working on a piece that might potentially be based on geometric figures would entail applying various kinds of isometry, both direct and indirect, such as translation, axial reflection, central symmetry, and central rotation. These procedures of composition are predicated on the introduction of a specific exact mode of musical creation and thought.

${ }^{9}$ The beginnings of the method outlined above may also be traced in certain segments of my work Batal, preludijumi za gudački orkestar (Batal: Preludes for String Orchestra), which was part of my doctoral artistic project, completed in 2014. 


\section{Works cited}

Gostuški, Dragutin: Vreme umetnosti: Prilog zasnivanju jedne opšte nauke o oblicima. Belgrade: Prosveta, 1968.

Латинчић, Драган: Микроинтервали у спектралној геометрији. Београд: Задужбина Андрејевић, 2015. [Latinčić, Dragan: Mikrointervali u spektralnoj geometriji. Belgrade: Zadužbina Andrejević, 2015.]

Латинчић, Драган: Примена микротоналности (а) у инструменталној блискоисточној и балканској музици фолклорне провенијенције, те (б) у инструменталној, камерној и оркестарској музици акустичког типа у савременој западној уметничкој музици (покушај заснивања једне аутономне стваралачко - композиторске конщепщије), докторски уметнички пројекат теоријска студија. Београд, 2014. [Latinčić, Dragan: Primena mikrotonalnosti (a) u instrumentalnoj blisko-istočnoj i balkanskoj muzici folklorne provenijencije, te (b) $u$ instrumentalnoj, kamernoj i orkestarskoj muzici akustičkog tipa u savremenoj zapadnoj umetničkoj muzici (pokušaj zasnivanja jedne autonomne stvaralačko-kompozitorske koncepcije), doctoral artistic project - theoretical study.Belgrade, 2014]

Латинчић, Драган: Спектрална тригонометрија (засниване универзалне музичкоматематичке анализе). Београд: Задужбина Андрејевић, 2017. [Latinčić, Dragan: Spektralna trigonometrija (zasnivanje univerzalne muzičko-matematičke analize). Belgrade: Zadužbina Andrejević, 2017]

Smith, David Eugene: History of Mathematics. Special Topics of Elementary Mathematics, Volume II. Boston: Ginn and Company, 1925.

Vendriks, Filip: Muzika u renesansi. Belgrade: Clio, 2005.

\section{Summary}

Many years of research in the field of micro-intervals in the theory and practice of Middle Eastern and North African folk music, as well as approximating the language of mathematics to elementary tools of music have produced results in several publications by the author. All of them were based on the method of projecting individual harmonics of the spectrum.

Projecting intervals or chords is a procedure that preserves one and the same elementary structure, but replaces its function. The vertical configuration of two or three different pitches (harmonic interval or harmonic chord) is projected into a horizontal configuration of two or more tonal lengths (projected interval or projected chord).

A projected harmonic octave comprising the ratio between the second harmonic and the fundamental would produce a rhythmic octave, comprising two equal rhythmic units. The method of projection entails an ultimate differentiation of the spectral domain into four regions. The method is likewise applicable on the other side of the spectrum, which extends inversely, below the fundamental of the spectrum. These are the sub-harmonics, which are derived by means of the old Pythagorean procedure called lambdoma. Compar- 
ing the left- and right-hand side of the spectrum is justified with the further examination of metric progression as well as rhythmic sequencing, by means of projecting collections of intervals from individual referential systems of different harmonics in the spectrum. On the left-hand side of the spectrum, projecting super-individual relations between different harmonics will always yield an iamb, while on the right-hand side the result will always be a trochee.

Kepler's proof of comparing circles and strings is the basis of measuring the angles of spectral intervals on both sides of the spectrum.

Using the method of metric-rhythmic projection, one may prove the applicability of the Pythagorean Theorem to the temporality of individual harmonics in the spectrum. The formulation thus derived would be applicable by way of the first Pythagorean triple (as well as all other Pythagorean triples), as follows: $(3 / x)^{2}+(4 / x)^{2}=(5 / x)^{2}$. The denominator serves to enable the recognition of partial segments of the fundamental of the spectrum that pertain to the system of a given harmonic in the spectrum. If we took one sixth of a given super-individual relation as the numerator, that would mean that the square of that structure would be recognisable from the referential system of the sixth harmonic: $(3 / 6)^{2}$ $+(4 / 6)^{2}=(5 / 6){ }^{2}$ If we simplify the formulation to $(1 / 2)^{2}+(2 / 3)^{2}=(5 / 6)^{2}$, we may conclude that the sum of squares formed on an octave and a twelfth equals a square formed on a super twelfth.

Relations applicable to the spectrum may be consistently transformed into the scalar and temporal system. On the basis of Aristoxenus's equivalence of distance and height, we may observe that the Pythagorean Theorem may also apply in the framework of scale intervals and chords. The type of transformation that preserves original distances and angles is called isometric transformation.

The method of isometric transformation proves the applicability of the Pythagorean as well as many other trigonometric theorems, such as the sine, cosine, and tangent theorem, as well as Mollweide's formula. 